\title{
Role of PTPN22 and CSK gene polymorphisms as predictors of susceptibility and clinical heterogeneity in patients with Henoch- Schönlein purpura (lgA vasculitis)
}

Raquel López-Mejías ${ }^{1 \dagger}$, Fernanda Genre ${ }^{1 \dagger}$, Sara Remuzgo-Martínez ${ }^{1 \dagger}$, Belén Sevilla Pérez ${ }^{2}$, Santos Castañeda ${ }^{3}$, Javier Llorca ${ }^{4}$, Norberto Ortego-Centeno², Begoña Ubilla', Verónica Mijares ${ }^{1}$, Trinitario Pina', Vanesa Calvo-Río ${ }^{1}$, Natalia Palmou', José A. Miranda-Filloy', Antonio Navas Parejo ${ }^{6}$, Diego Argila, Javier Sánchez-Pérez ${ }^{7}$, Esteban Rubio ${ }^{8}$, Manuel León Luque ${ }^{8}$, Juan María Blanco-Madrigal ${ }^{9}$, Eva Galíndez-Aguirregoikoa ${ }^{9}$, J. Gonzalo Ocejo-Vinyals ${ }^{10}$, Javier Martín ${ }^{11}$, Ricardo Blanco ${ }^{1}$ and Miguel A. González-Gay ${ }^{1,12^{*}}$

\begin{abstract}
Introduction: To determine whether the PTPN22 (protein tyrosine phosphatase nonreceptor 22)/CSK (c-src tyrosine kinase) pathway is implicated in the susceptibility and clinical heterogeneity of Henoch-Schönlein purpura (HSP) in the largest series of Caucasian HSP patients ever assessed for genetic studies.

Methods: A set of 329 Spanish patients diagnosed with HSP fulfilling the American College of Rheumatology and the Michel et al. classification criteria and 515 sex and ethnically matched controls were recruited in this study. Two well-known CSK (CSK rs34933034 and CSK rs 1378942) and two functional PTPN22 (PTPN22 rs2476601 (R620W) and PTPN22 rs33996649 (R263Q)) polymorphisms, previously associated with autoimmunity, were genotyped with TaqMan single nucleotide polymorphism (SNP) genotyping assays.

Results: No significant differences in the genotype and allele frequencies between HSP patients and controls were observed when the CSK rs34933034, CSK rs1378942, PTPN22 rs2476601 (R620W) and PTPN22 rs33996649 (R263Q) polymorphisms were analyzed independently. In keeping with this observation, no significant differences were found when we assessed these polymorphisms combined conforming haplotypes. In addition, there were no differences in the allele or genotype frequencies when HSP patients were stratified according the age at disease onset, sex, presence of arthralgia/arthritis, nephritis or gastrointestinal manifestations.
\end{abstract}

Conclusions: Our results do not support association between PTPN22/CSK and HSP.

\footnotetext{
* Correspondence: miguelaggay@hotmail.com

Drs Miguel A. González-Gay and Ricardo Blanco share senior authorship in this study.

${ }^{\dagger}$ Equal contributors

${ }^{1}$ Epidemiology, Genetics and Atherosclerosis Research Group on Systemic Inflammatory Diseases, Rheumatology Division, Hospital Universitario Marqués de Valdecilla, IDIVAL, Avenida de Valdecilla, s/n, 39008 Santander, Spain

${ }^{12}$ Cardiovascular Pathophysiology and Genomics Research Unit, School of Physiology, Faculty of Health Sciences, University of the Witwatersrand, 7 York Road, Parktown 2193, Johannesburg, South Africa

Full list of author information is available at the end of the article
}

(c) 2015 López-Mejías et al. Open Access This article is distributed under the terms of the Creative Commons Attribution 4.0 International License (http://creativecommons.org/licenses/by/4.0/), which permits unrestricted use, distribution, and reproduction in any medium, provided you give appropriate credit to the original author(s) and the source, provide a link to the Creative Commons license, and indicate if changes were made. The Creative Commons Public Domain Dedication waiver (http://creativecommons.org/publicdomain/zero/1.0/) applies to the data made available in this article, unless otherwise stated. 


\section{Introduction}

Henoch-Schönlein purpura (HSP), also called immunoglobulin A (IgA) vasculitis, is a leukocytoclastic vasculitis characterized by IgA-dominant immune deposits involving mainly the skin as well as other tissues [1]. HSP is more common in children but is not exceptional in adults [1]. The main feature of this vasculitis is a palpable purpura involving predominantly the lower extremities. Besides skin involvement, HSP often causes joint pain and gastrointestinal complications [2]. Nevertheless, renal manifestations constitute the most serious complications of HSP [2] and long-term morbidity and mortality in these patients are mainly due to renal involvement. Although the molecular bases underlying the origin of HSP have not been elucidated yet, environmental and socioeconomical factors are suggested to be involved in the disease pathogenesis [3]. Moreover, the relevance of genetic variants in both susceptibility and HSP clinical heterogeneity has been demonstrated [3-5].

Protein tyrosine phosphatases (PTPs) are critical regulators of $\mathrm{T}$ cell signal transduction [6]. Among these molecules, the lymphoid-specific phosphatase (Lyp) is a $110-\mathrm{kDa}$ PTP encoded by the gene PTPN22 (protein tyrosine phosphatase nonreceptor 22). Lyp is expressed in lymphocytes where it physically associates to the SH3 domain of CSK (c-src tyrosine kinase) [6]. Since this binding has been considered as the most powerful inhibitor of $\mathrm{T}$ cell activation, the PTPN22/CSK pathway has been proposed as a master regulator of autoimmunity [7] being a molecular pathway shared by several inflammatory pathologies. In accordance with that, some studies have described an association between two well-known genetic variants located in the CSK gene (CSK rs34933034 and CSK rs1378942) and several immune-mediated disorders such as systemic lupus erythematosus and systemic sclerosis in Caucasian patients $[8,9]$. Additionally, a relationship between two functional genetic variants located in the PTPN22 gene (PTPN22 rs2476601 (R620W) and PTPN22 rs33996649 (R263Q)) and some inflammatory diseases (such as type I diabetes, systemic lupus erythematosus and rheumatoid arthritis) has been demonstrated in Caucasians $[6,10,11]$. In line with that, although the genetic influence of PTPN22/ CSK in several vasculitides (such as giant cell arteritis, Behçet's disease and antineutrophil cytoplasmic antibody (ANCA)-associated vasculitides [12-14]) has been demonstrated, there is scarce information on the role of PTPN22/CSK in HSP. In this regard, only a small cohort of Caucasian patients was assessed to establish the potential implication of the PTPN22 rs2476601 (R620W) genetic variant in HSP [15].

Taking these considerations together, this study aimed at investigating whether the PTPN22/CSK pathway is actually involved in both HSP susceptibility and clinical heterogeneity. For this purpose, we analyzed two well- known CSK (CSK rs34933034 and CSK rs1378942) and two functional PTPN22 (PTPN22 rs2476601 (R620W) and PTPN22 rs33996649 (R263Q)) polymorphisms, previously associated with autoimmunity, in the largest series of Caucasian patients with this vasculitis ever assessed for genetic studies.

\section{Methods}

\section{Patients and study protocol}

A set of 329 Spanish patients with cutaneous vasculitis who fulfilled Michel et al. [16] classification criteria for HSP were included in the present study. According to them, they were classified as having HSP if they fulfilled three or more of the following characteristics: palpable purpura, bowel angina, gastrointestinal bleeding, macroscopic or microscopic hematuria, age at disease onset $\leq 20$ years, and no previous history of medications prior to the onset of the disease. Typically, HSP is more common in children. Although less common, HSP may also occur in adults (in individuals older than 20 years). Therefore, the development of this vasculitis in an adult was not an exclusion criterion for the diagnosis of HSP. However, adults presenting with palpable purpura required the presence of other manifestations (other criteria proposed by Michel et al.) and, of course, the exclusion of other vasculitis such as ANCA-associated vasculitis was required in these cases. Also, all patients included in this series were required to fulfill the American College of Rheumatology classification criteria for HSP [17].

This collaborative study started 5 years ago. Because of that, the median duration of follow-up of the patients was 1.5 years. Nevertheless, some patients who had suffered this vasculitis before and who still attended outpatients clinics were retrospectively recruited.

Blood samples were obtained from patients recruited from Hospital Universitario Lucus Augusti (Lugo), Hospital Universitario Marqués de Valdecilla (Santander), Hospital Universitario La Princesa (Madrid), Hospital Universitario San Cecilio (Granada), Hospital Universitario Virgen del Rocío (Sevilla) and Hospital Universitario de Basurto (Bilbao). Information on the main clinical features of the whole series of 329 HSP Spanish patients recruited in this study is shown in Table 1. Joint manifestations were defined if arthralgia or peripheral arthritis was observed on examination. For gastrointestinal (GI) manifestations, bowel angina was considered present if there was diffuse abdominal pain that worsened after meals or bowel ischemia usually with bloody diarrhea. GI bleeding was defined as the presence of melena, hematochezia, or a positive test for occult blood in the stool. Renal manifestations were defined to be present if at least one of the following findings was observed: hematuria ( $\geq 5 \mathrm{red}$ blood cells/hpf), proteinuria ( $>300 \mathrm{mg} / 24 \mathrm{~h}$ ), nephrotic syndrome $\left(1 \mathrm{~g} /\right.$ day $/ \mathrm{m}^{2}$ body surface area or $>3.5 \mathrm{~g} /$ day 
Table 1 Main clinical features of a series of 329 Spanish patients with HSP

\begin{tabular}{ll}
\hline Main characteristics & $\%(\mathrm{n} / \mathrm{N})$ \\
\hline Children (age $\leq 20$ years)/adults (age >20 years) & $267 / 62$ \\
Male/female & $168 / 161$ \\
Age at the onset of the disease (years, median [IQR]) & $7[5-18]$ \\
Duration of follow-up (years, median [IQR]) & $1.5[1-4]$ \\
Palpable purpura and/or maculopapular rash & $100(329 / 329)$ \\
Joint manifestations (arthralgia and/or arthritis) & $55.6(183 / 329)$ \\
Gastrointestinal manifestations (if "a" and/or "b") & $52.9(174 / 329)$ \\
a) Bowel angina & $51.4(169 / 329)$ \\
b) Gastrointestinal bleeding & $15.5(51 / 329)$ \\
Renal manifestations (if any of the following & $34.6(114 / 329)$ \\
characteristics) & \\
a) Hematuria & $33.7(111 / 329)$ \\
b) Proteinuria & $32.2(106 / 329)$ \\
c) Nephrotic syndrome & $3.0(10 / 329)$ \\
d) Nephritic syndrome & $1.2(4 / 329)$ \\
\hline
\end{tabular}

HSP Henoch-Schönlein purpura, IQR interquartile range

proteinuria with plasma albumin $<25 \mathrm{~g} / \mathrm{l}$, with or without edema) and nephritic syndrome (i.e., hematuria with at least two of the following: hypertension, raised plasma urea or creatinine, and oliguria). Renal and severe GI manifestations were frequently observed in $34.6 \%$ and $52.9 \%$ of these patients.

A set of 515, sex and ethnically matched controls (median [interquartile range (IQR)]: 48 [27-62] years; $51 \%$ males and $49 \%$ females) without history of cutaneous vasculitis or any other autoimmune disease constituted by blood donors from National DNA Bank Repository (Salamanca, Spain), was also included in the study.

A subject's written consent was obtained according to the declaration of Helsinki, and the study was approved by the Ethics Committees of Galicia for Hospital Universitario Lucus Augusti, of Cantabria for Hospital Universitario Marqués de Valdecilla, of Madrid for Hospital Universitario La Princesa, of Andalucía for Hospital Universitario San Cecilio and Hospital Universitario Virgen del Rocío, and of País Vasco for Hospital Universitario de Basurto.

\section{Genotyping}

Genomic deoxyribonucleic acid (DNA) was extracted from peripheral blood mononuclear cells using standard methods. The selection of the single nucleotide polymorphisms (SNPs) was based on their previous association with several inflammatory diseases and some types of vasculitis. In this regard, two well-known SNPs located within CSK, CSK rs34933034 (C_60143137_10) and CSK rs1378942 (C__1642446_10), and two functional SNPs located within PTPN22, PTPN22 rs2476601 (R620W) (C_16021387_20) and PTPN22 rs33996649 (R263Q)
(C_25937239_30), were genotyped using TaqMan SNP genotyping assays in a $7900 \mathrm{HT}$ real-time polymerase chain reaction (PCR) system, according to the conditions recommended by the manufacturer (Applied Biosystems, Foster City, CA, USA). PCR was carried out in a total reaction volume of $4 \mu \mathrm{l}$ with the following amplification protocol: denaturation at $95{ }^{\circ} \mathrm{C}$ for $10 \mathrm{~min}$, followed by 45 cycles of denaturation at $92{ }^{\circ} \mathrm{C}$ for $15 \mathrm{~s}$ and then annealing and extension at $60{ }^{\circ} \mathrm{C}$ for $1 \mathrm{~min}$. Negative controls and duplicate samples were included to check the accuracy of genotyping.

\section{Statistical analysis}

All genotype data were checked for deviation from HardyWeinberg equilibrium (HWE) using http://ihg.gsf.de/cgi-bin/ hw/hwa1.pl [18]. Statistical power for the study was calculated using CaTS - the power calculator for two-stage association studies (http://www.sph.umich.edu/csg/abecasis/CaTS/) [19].

First, comparisons were performed considering all SNPs independently. Both allelic and genotypic frequencies were calculated and compared by $\chi^{2}$ or Fisher tests when necessary (expected values below 5). Strength of association was estimated using odds ratios (OR) and $95 \%$ confidence intervals (CI). Allelic ORs for CSK and PTPN22 polymorphisms were estimated using the major allele as a reference. Genotype ORs for CSK polymorphisms were estimated in three models: (1) using the GG genotype as reference for CSK rs34933034, which was compared with each other genotype (i.e.: GA vs. GG and AA vs. GG) and the AA genotype as reference for CSK rs1378942, which was compared with each other genotype (i.e.: AC vs. AA and CC vs. AA); (2) the dominant model: AA + GA vs. GG (reference) for CSK rs34933034 and CC + AC vs. AA (reference) for CSK rs1378942; (3) the recessive model: AA vs. GG + GA (reference) for CSK rs34933034 and CC vs. AA + AC (reference) for CSK rs1378942.

Subsequently, allelic combinations (haplotypes) of both CSK and PTPN22 polymorphisms were performed in order to uncover hidden signals in the PTPN22/CSK pathway. Haplotypes were constructed using Haploview v4.2 software; haplotypic frequencies were compared by $X^{2}$ test and the strength of association was estimated by OR (using the major haplotype as a reference) and $95 \%$ CI.

All analyses were performed with STATA statistical software 12/SE (Stata Corp., College Station, TX, USA).

\section{Results}

Differences in genotype and allele frequencies between HSP patients and controls

The CSK rs34933034, CSK rs1378942, PTPN22 rs2476601 (R620W) and PTPN22 rs33996649 (R263Q) genotypes distribution were in Hardy-Weinberg equilibrium (Table 2) and for these four SNPs the genotyping success in HSP 
Table 2 Genotype and allele frequencies of CSK and PTPN22 gene polymorphisms in HSP patients and controls

\begin{tabular}{|c|c|c|c|c|c|c|c|c|c|}
\hline \multirow[b]{2}{*}{ SNP } & \multirow[b]{2}{*}{ Locus } & \multirow{2}{*}{$\begin{array}{l}\text { Change } \\
1 / 2\end{array}$} & \multirow[b]{2}{*}{ Sample set } & \multirow[b]{2}{*}{ N } & \multicolumn{3}{|c|}{ Genotype, n (\%) } & \multicolumn{2}{|c|}{ Allele test } \\
\hline & & & & & $1 / 1$ & $1 / 2$ & $2 / 2$ & $p$ & OR $\left[95 \% \mathrm{Cl}^{\mathrm{a}}\right.$ \\
\hline \multirow[t]{2}{*}{ rs34933034 } & CSK & $\mathrm{G} / \mathrm{A}$ & HSP patients & 329 & $219(66.6)$ & $96(29.2)$ & $14(4.3)$ & 0.96 & 1.00 [0.77-1.28] \\
\hline & & & Controls $^{\mathrm{b}}$ & 515 & $337(65.4)$ & 161 (31.3) & $17(3.3)$ & & \\
\hline \multirow[t]{2}{*}{ rs1378942 } & CSK & $\mathrm{A} / \mathrm{C}$ & HSP patients & 329 & $111(33.7)$ & $170(51.7)$ & $48(14.6)$ & 0.22 & 1.13 [0.93-1.38] \\
\hline & & & Controls $^{c}$ & 515 & 193 (37.5) & $258(50.1)$ & $64(12.4)$ & & \\
\hline \multirow[t]{2}{*}{ rs2476601 } & PTPN22 & $\mathrm{G} / \mathrm{A}$ & HSP patients & 329 & 285 (86.6) & $42(12.8)$ & $2(0.6)$ & 0.16 & 1.34 [0.89-1.99] \\
\hline & & & Controls $^{d}$ & 515 & 462 (89.7) & $51(9.9)$ & $2(0.4)$ & & \\
\hline \multirow[t]{2}{*}{ rs33996649 } & PTPN22 & $C / T$ & HSP patients & 329 & $314(95.4)$ & $15(4.6)$ & 0 & 0.15 & 0.67 [0.36-1.22] \\
\hline & & & Controls $^{\mathrm{e}}$ & 515 & $480(93.2)$ & $34(6.6)$ & $1(0.2)$ & & \\
\hline
\end{tabular}

HSP Henoch-Schönlein purpura, SNP single nucleotide polymorphism, N number of patients, OR [95\% Cl] odds ratio with $95 \%$ confidence interval

${ }^{\mathrm{a}}$ For the minor allele

${ }^{b}$ pHardy-Weinberg equilibrium $=0.67$

${ }^{c}$ pHardy-Weinberg equilibrium $=0.12$

$d_{\text {pHardy-Weinberg equilibrium }=0.64}$

$\mathrm{e}_{\mathrm{pH}}$ ardy-Weinberg equilibrium $=0.63$

patients and controls was greater than $98 \%$. Accordingly, less than $2 \%$ of the samples failed the genotyping process and were removed from our study. This study had $>80 \%$ of power to detect genotypic OR $>1.4$ for CSK rs34933034, CSK rs1378942, PTPN22 rs2476601 (R620W) and PTPN22 rs33996649 (R263Q).

Table 2 describes the distribution of CSK rs34933034, CSK rs1378942, PTPN22 rs2476601 (R620W) and PTPN22 rs33996649 (R263Q) (considering these genetic variants independently) in HSP patients and controls. As shown in Table 2, no significant differences in the genotype and allele frequencies of these four SNPs between HSP patients and controls were observed ( $p>0.10$ in all the cases). Additionally, no statistically significant differences were found when we analyzed CSK polymorphisms under different genetic models such as codominant, dominant and recessive (Table S1 in Additional file 1). However, due the relatively low number of PTPN22 mutant homozygous, these genetic models could not be calculated for PTPN22 polymorphisms.

In a further step, we assessed CSK rs34933034 and CSK rs1378942 combined conforming haplotypes. However, the haplotype analysis did not yield additional information, as no differences between HSP patients and controls were found (Table S2 in Additional file 2). It was also the case when the analysis of PTPN22 rs2476601 (R620W) and PTPN22 rs33996649 (R263Q) combined conforming haplotypes was performed (Table S2 in Additional file 2).

\section{Differences in genotype and allele frequencies between HSP patients according to the age at disease onset} Since HSP is generally a benign and self-limited pathology in children and a more severe condition in adults [2], in our study we also assessed if potential differences in CSK rs34933034, CSK rs1378942, PTPN22 rs2476601
(R620W) and PTPN22 rs33996649 (R263Q) could exist in HSP patients stratified according to the age at disease onset. However, as shown in Table 3A and B, no differences in genotype and allele frequencies were detected between HSP in children (age $\leq 20$ years) and adults (age $>20$ years).

\section{Differences in genotype and allele frequencies between HSP patients according to the presence of nephritis and gastrointestinal manifestations}

The allele and genotype frequencies were also examined in HSP patients stratified by the presence of nephritis. Nevertheless, no statistically significant differences between HSP patients with or without renal manifestations were observed (Table 3A and B). This was also the case when HSP patients with severe GI complications (GI bleeding or bowel angina) were compared with those without these complications (Table 3A and B).

\section{Differences in genotype and allele frequencies between HSP patients according to sex and the presence of joint manifestations (arthralgia or arthritis)}

Finally, we assessed if potential differences in genotype and allele frequencies could exist in HSP patients stratified according to sex and the presence of arthralgia or arthritis. However, no statistically significant differences in the genotype and allele frequencies were found between HSP patients stratified according to sex (Table S3 in Additional file 3). It was also the case when HSP patients were stratified according to the presence or absence of joint manifestations (Table S3 in Additional file 3).

\section{Discussion}

Accumulating evidences clearly suggest that a common genetic component may underlie different autoimmune diseases. PTPN22/CSK pathway has been postulated as a 
Table 3 Genotype and allele frequencies of CSK and PTPN22 gene polymorphisms in HSP patients according to the age at disease onset and the presence/absence of renal and Gl manifestations

\begin{tabular}{|c|c|c|c|c|c|c|c|c|c|c|c|c|}
\hline \multicolumn{13}{|c|}{ A. CSK polymorphisms } \\
\hline \multirow[t]{2}{*}{ SNP } & \multicolumn{4}{|c|}{ Children (Age $\leq 20$ years) } & \multicolumn{4}{|c|}{ HSP with renal manifestations ${ }^{a}$} & \multicolumn{4}{|c|}{ HSP with GI manifestations ${ }^{\mathrm{b}}$} \\
\hline & Yes $(n=267)$ & No $(n=62)$ & $p$ & OR $[95 \% \mathrm{Cl}]$ & Yes $(n=114)$ & No $(n=215)$ & $p$ & OR $[95 \% \mathrm{Cl}]$ & Yes $(n=174)$ & No $(n=155)$ & $p$ & OR $[95 \% \mathrm{Cl}]$ \\
\hline \multicolumn{13}{|c|}{ CSK rs34933034 } \\
\hline \multicolumn{13}{|c|}{ Genotypes } \\
\hline GG & $172(64.4)$ & $39(62.9)$ & - & Ref. & $73(64.0)$ & $138(64.2)$ & - & Ref. & $122(70.1)$ & $97(62.6)$ & - & Ref. \\
\hline GA & $83(31.1)$ & $21(33.9)$ & 0.72 & $0.90[0.48-1.71]$ & $37(32.4)$ & $65(30.2)$ & 0.77 & 1.08 [0.64-1.81] & $47(27.0)$ & 49 (31.6) & 0.27 & $0.76[0.46-1.27]$ \\
\hline AA & $12(4.5)$ & $2(3.2)$ & 0.69 & $1.36[0.28-12.9]$ & $4(3.5)$ & $12(5.6)$ & 0.43 & $0.63[0.14-2.18)$ & $5(2.9)$ & $9(5.8)$ & 0.15 & $0.44[0.11-1.53]$ \\
\hline \multicolumn{13}{|c|}{ Alleles } \\
\hline G & $427(80.0)$ & $99(79.8)$ & - & Ref. & $183(80.2)$ & $341(79.3)$ & - & Ref. & $291(83.6)$ & $243(78.4)$ & - & Ref. \\
\hline A & $107(20.0)$ & $25(20.2)$ & 0.98 & 0.99 [0.60-1.69] & 45 (19.7) & 89 (20.7) & 0.77 & $0.94[0.62-1.43]$ & $57(16.4)$ & 67 (21.6) & 0.09 & 0.71 [0.47-1.07] \\
\hline \multicolumn{13}{|c|}{ CSK rs1378942 } \\
\hline \multicolumn{13}{|c|}{ Genotypes } \\
\hline AA & 95 (35.6) & $18(29.0)$ & - & Ref. & 44 (38.6) & $69(32.1)$ & - & Ref. & $64(36.8)$ & $47(30.3)$ & - & Ref. \\
\hline$A C$ & $138(51.7)$ & $32(51.6)$ & 0.53 & $0.82[0.41-1.60]$ & $58(50.9)$ & $112(52.1)$ & 0.41 & $0.81[0.48-1.37]$ & $89(51.1)$ & $81(52.3)$ & 0.38 & 0.81 [0.48-1.34] \\
\hline CC & $34(12.7)$ & $12(19.4)$ & 0.14 & $0.54[0.22-1.36]$ & $12(10.5)$ & $34(15.8)$ & 0.12 & $0.55[0.24-1.24]$ & $21(12.1)$ & $27(17.4)$ & 0.11 & $0.57[0.27-1.20]$ \\
\hline \multicolumn{13}{|c|}{ Alleles } \\
\hline A & $328(61.4)$ & $68(54.8)$ & - & Ref. & $146(64.0)$ & $250(58.1)$ & - & Ref. & $217(62.4)$ & $175(56.5)$ & - & Ref. \\
\hline C & 206 (38.6) & $56(45.2)$ & 0.18 & $0.76[0.50-1.16]$ & $82(36.0)$ & $180(41.9)$ & 0.14 & 0.78 [0.55-1.10] & 131 (37.6) & $135(43.5)$ & 0.12 & 0.78 [0.57-1.08] \\
\hline \multicolumn{13}{|c|}{ B. PTPN22 polymorphisms } \\
\hline \multirow[t]{2}{*}{ SNP } & \multicolumn{4}{|c|}{ Children (Age $\leq 20$ years) } & \multicolumn{4}{|c|}{ HSP with renal manifestations ${ }^{a}$} & \multicolumn{4}{|c|}{ HSP with Gl manifestations ${ }^{b}$} \\
\hline & Yes $(n=267)$ & No $(n=62)$ & $p$ & OR $[95 \% \mathrm{Cl}]$ & Yes $(n=114)$ & No $(n=215)$ & $p$ & OR $[95 \% \mathrm{Cl}]$ & Yes $(n=174)$ & No $(n=155)$ & $p$ & OR $[95 \% \mathrm{Cl}]$ \\
\hline \multicolumn{13}{|c|}{ PTPN22 rs2476601 } \\
\hline \multicolumn{13}{|c|}{ Genotypes } \\
\hline GG & $229(85.8)$ & $56(90.3)$ & - & Ref. & $99(86.8)$ & $186(86.5)$ & - & Ref. & $152(87.4)$ & $133(85.8)$ & - & Ref. \\
\hline GA & 37 (13.9) & $5(8.1)$ & 0.23 & $1.81[0.67-6.16]$ & $15(13.2)$ & $26(12.1)$ & 0.82 & $1.08[0.51-2.24]$ & $22(12.6)$ & $20(12.9)$ & 0.91 & $0.96[0.48-1.95]$ \\
\hline AA & $1(0.4)$ & $1(1.6)$ & 0.28 & $0.24[0.003-19.5]$ & 0 & $3(1.4)$ & - & - & 0 & $2(1.3)$ & - & - \\
\hline \multicolumn{13}{|c|}{ Alleles } \\
\hline G & $495(92.7)$ & $117(94.4)$ & - & Ref. & $213(93.4)$ & $398(92.6)$ & - & Ref. & $326(93.7)$ & $286(92.3)$ & - & Ref. \\
\hline A & $39(7.3)$ & $7(5.6)$ & 0.51 & $1.32[0.56-3.58]$ & $15(6.6)$ & $32(7.4)$ & 0.68 & $0.88[0.43-1.71]$ & $22(6.3)$ & $24(7.7)$ & 0.48 & $0.80[0.42-1.53]$ \\
\hline
\end{tabular}


Table 3 Genotype and allele frequencies of CSK and PTPN22 gene polymorphisms in HSP patients according to the age at disease onset and the presence/absence of renal and Gl manifestations (Continued)

\begin{tabular}{|c|c|c|c|c|c|c|c|c|c|c|c|c|}
\hline \multicolumn{13}{|c|}{ PTPN22 rs33996649 } \\
\hline \multicolumn{13}{|c|}{ Genotypes } \\
\hline CC & $256(95.9)$ & $58(93.5)$ & - & Ref. & 108 (94.7) & $206(95.8)$ & - & Ref. & $165(94.8)$ & 149 (96.1) & - & Ref. \\
\hline$C T$ & $11(4.1)$ & $4(6.5)$ & 0.43 & $0.62[0.18-2.78]$ & $6(5.3)$ & $9(4.2)$ & 0.66 & $1.27[0.36-4.12]$ & $9(5.2)$ & $6(3.9)$ & 0.57 & $1.35[0.42-4.74]$ \\
\hline$\pi$ & 0 & 0 & - & - & 0 & 0 & - & - & 0 & 0 & - & - \\
\hline \multicolumn{13}{|c|}{ Alleles } \\
\hline C & $523(97.9)$ & $120(96.8)$ & - & Ref. & $222(97.4)$ & 421 (97.9) & - & Ref. & 339 (97.4) & $304(98.1)$ & - & Ref. \\
\hline $\mathrm{T}$ & $11(2.1)$ & $4(3.2)$ & 0.43 & $0.63[0.18-2.77]$ & $6(2.6)$ & $9(2.1)$ & 0.66 & $1.26[0.37-4.03]$ & $9(2.6)$ & $6(1.9)$ & 0.58 & $1.35[0.42-4.65$ \\
\hline
\end{tabular}

HSP Henoch-Schönlein purpura, GI gastrointestinal, SNP single nucleotide polymorphism, OR odds ratio, Cl confidence interval

alf any of the following characteristics: hematuria, proteinuria, nephrotic syndrome and/or nephritic syndrome

b If bowel angina and/or gastrointestinal bleeding 
potential common genetic factor shared for different autoimmune disorders [6, 8-11].

The vasculitides constitute a heterogeneous group of diseases that often have overlapping clinical and pathological manifestations [20]. Although their complex etiology is far from being completely understood, genetic factors appear to influence the development and progression of these conditions [3-5]. In this regard, an implication of PTPN22/CSK in the susceptibility to giant cell arteritis, Behçet's disease and ANCA-associated vasculitides has been described in Caucasians [12-14]. However, the potential influence of PTPN22/CSK in HSP remains unclear. With respect to this, a few years ago Orozco et al. did not observe a significant association between the PTPN22 gene polymorphism and HSP [15]. This study was based on the analysis of a single functional polymorphism (PTPN22 rs2476601 (R620W)) and it was performed in a small cohort of only 57 HSP patients [15]. Accordingly, a potential false negative result could not be excluded due to the underpowered sample size of the study. Because of that, in an attempt to establish if PTPN22/CSK is actually involved in HSP, we analyzed two well-known CSK and two functional PTPN22 polymorphisms, previously associated with autoimmunity, in the largest series of Caucasian patients with this vasculitis ever assessed for genetic studies. Our results do not show an implication of PTPN22/CSK polymorphisms in the susceptibility to HSP.

The PTPN22/CSK pathway acts as an inhibitor of $\mathrm{T}$ cell signaling [6]. T cells appear to be more relevant than $\mathrm{B}$ cells in some autoimmune diseases whereas in others it seems to be the opposite. With respect to this, the relevance of IgA-dominant immune deposits in HSP development suggests that the implication of $\mathrm{T}$ cells in HSP may be less important than in other autoimmune diseases or other types of vasculitis such as, for example, in giant cell arteritis [1]. In this regard, the lack of association between PTPN22/CSK and susceptibility and clinical spectrum of HSP found in our study supports the hypothesis that B cells are more important than T cells in HSP.

In keeping with our findings, no association with PTPN22/CSK was also described in other immunemediated diseases such as multiple sclerosis and ankylosing spondylitis $[21,22]$. Taken together, the results in terms of PTPN22/CSK association with autoimmune diseases support the notion that different pathogenic mechanisms are involved in the development of polygenic disorders.

The results derived from the present study may be of potential clinical interest. In this respect, since small molecule inhibitors of Lyp would have preventative and/or therapeutic efficacy in patients with a wide range of autoimmune diseases (especially in individuals who are carriers of the PTPN22 rs2476601 (R620W) genetic variant), the lack of association between the PTPN22/CSK polymorphisms pathway and HSP indicate that small molecule inhibitors of Lyp may not have a beneficial effect in patients with this vasculitis.

To conclude, although our cohort of HSP patients constitutes the largest series of Caucasian patients with this vasculitis ever assessed for genetic studies, further large collaborative studies in other populations are needed to fully establish the role of $\mathrm{T}$ cell activation polymorphisms in HSP.

\section{Conclusions}

Our results do not support an association between PTPN22/CSK gene polymorphisms and HSP. Consequently, small molecule inhibitors of Lyp may not have a beneficial effect in patients with HSP.

\section{Additional files}

Additional file 1: Table S1. Different genetic models of inheritance for CSK polymorphisms. (DOC $28 \mathrm{~kb}$ )

Additional file 2: Table S2. CSK and PTPN22 haplotype analysis. (DOC $33 \mathrm{~kb}$ )

Additional file 3: Table S3. Genotype and allele frequencies of CSK and PTPN22 gene polymorphisms in HSP patients according to sex and the presence of joint manifestations (arthralgia or arthritis). (DOC 67 kb)

\section{Abbreviations}

ANCAs: antineutrophil cytoplasmic antibodies; Cl: confidence interval; CSK: c-src tyrosine kinase; DNA: deoxyribonucleic acid; Gl: gastrointestinal; HSP: Henoch-Schönlein purpura; HWE: Hardy-Weinberg equilibrium; IgA: immunoglobulin-A; IQR: interquartile range; Lyp: lymphoid-specific phosphatase; OR: odds ratio; PCR: polymerase chain reaction; PTPN22: protein tyrosine phosphatase nonreceptor 22; PTPs: protein tyrosine phosphatases; SNPs: single nucleotide polymorphisms.

\section{Competing interests}

The authors declare that they have no competing interests.

\section{Authors' contributions}

RL-M, FG and SR-M participated in the design of the study, data analysis and helped to draft the manuscript. SC, NOC and JM were involved in the acquisition and interpretation of data and in revising it critically for important intellectual content. JL carried out the analysis and interpretation of the data and helped to draft the manuscript. BSP, BU, VM, TP, VC-R, NP, JAMF, ANP, DA, JSP, ER, MLL, JMB-M, EG-A and JGOV participated in the acquisition and interpretation of data and helped to draft the manuscript. RB and MAG-G made substantial contributions to conception and design of the study, acquisition of data and coordination, helped to draft the manuscript and gave final approval of the version to be published. All authors read and approved the manuscript for publication.

\section{Acknowledgements}

We wish to thank all the patients with HSP and controls who participated to make this study possible. We want to specially thank Patricia Fuentevilla Rodríguez, María Del Camino Villa Llamazares and María Eugenia Cuadrado Mantecón for their technical assistance.

This study was supported by a grant from "Fondo de Investigaciones Sanitarias" PI12/00193 (Spain). RLM is a recipient of a Sara Borrell postdoctoral fellowship from the Instituto de Salud Carlos III at the Spanish Ministry of Health (Spain) (CD12/00425). FG and BU are supported by funds from the RETICS Program (RIER) (RD12/0009/0013). 


\section{Author details}

${ }^{1}$ Epidemiology, Genetics and Atherosclerosis Research Group on Systemic Inflammatory Diseases, Rheumatology Division, Hospital Universitario Marqués de Valdecilla, IDIVAL, Avenida de Valdecilla, s/n, 39008 Santander, Spain. ${ }^{2}$ Department of Medicine, Hospital Universitario San Cecilio, Calle Dr. Oloriz, 16, 18012 Granada, Spain. ${ }^{3}$ Rheumatology Department, Hospital Universitario La Princesa, IIS-Princesa, Calle Diego de León, 62, 28006 Madrid, Spain. ${ }^{4}$ Epidemiology and Computational Biology Department, School of Medicine, University of Cantabria, and CIBER Epidemiología y Salud Pública (CIBERESP), IDIVAL, Avenida Cardenal Herrera Oria, s/n, 39011 Santander, Spain. ${ }^{5}$ Division of Rheumatology, Hospital Universitario Lucus Augusti, Calle Dr. Ochoa, s/n, 27004 Lugo, Spain. ${ }^{6}$ Nephrology Department, Hospital Universitario San Cecilio, Calle Dr. Oloriz, 16, 18012 Granada, Spain.

${ }^{7}$ Dermatology Department, Hospital Universitario La Princesa, IIS-Princesa, Calle Diego de León, 62, 28006 Madrid, Spain. ${ }^{8}$ Rheumatology Department, Hospital Universitario Virgen del Rocío, Avenida Manuel Siurot, s/n, 41013 Sevilla, Spain. ${ }^{9}$ Rheumatology Department, Hospital Universitario de Basurto, Avenida de Montevideo, 18, 48013 Bilbao, Spain. ${ }^{10}$ Immunology Department, Hospital Universitario Marqués de Valdecilla, Avenida de Valdecilla, s/n, 39008 Santander, Spain. ${ }^{11}$ Institute of Parasitology and Biomedicine López-Neyra, CSIC, Avenida del Conocimiento, s/n, 18016 Granada, Spain. ${ }^{12}$ Cardiovascular Pathophysiology and Genomics Research Unit, School of Physiology, Faculty of Health Sciences, University of the Witwatersrand, 7 York Road, Parktown 2193, Johannesburg, South Africa.

Received: 1 June 2015 Accepted: 23 September 2015

Published online: 13 October 2015

\section{References}

1. González-Gay MA, García-Porrúa C. Epidemiology of the vasculitides. Rheum Dis Clin North Am. 2001;27:729-49.

2. García-Porrúa C, Calviño MC, Llorca J, Couselo JM, González-Gay MA. Henoch-Schönlein purpura in children and adults: clinical differences in a defined population. Semin Arthritis Rheum. 2002;32:149-56.

3. Wyatt RJ, Julian BA. IgA nephropathy. N Engl J Med. 2013:368:2402-14.

4. López-Mejías R, Genre F, Pérez BS, Castañeda S, Ortego-Centeno N, Llorca J, et al. HLA-DRB1 association with Henoch-Schonlein purpura. Arthritis Rheumatol. 2015;67:823-7.

5. López-Mejías R, Genre F, Sevilla Pérez B, Castañeda S, Ortego-Centeno N, Llorca J, et al. Association of HLA-B*41:02 with Henoch-Schönlein purpura (IgA vasculitis) in Spanish individuals irrespective of the HLA-DRB1 status. Arthritis Res Ther. 2015;17:102.

6. Bottini N, Musumeci L, Alonso A, Rahmouni S, Nika K, Rostamkhani M, et al. A functional variant of lymphoid tyrosine phosphatase is associated with type I diabetes. Nat Genet. 2004;36:337-8.

7. Cloutier J, Veillette A. Cooperative inhibition of T-cell antigen receptor signaling by a complex between a kinase and a phosphatase. J Exp Med. 1999:189:111-21.

8. Manjarrez-Orduño N, Marasco E, Chung SA, Katz MS, Kiridly JF, Simpfendorfer KR, et al. CSK regulatory polymorphism is associated with systemic lupus erythematosus and influences B-cell signaling and activation. Nat Genet. 2012:44:1227-30.

9. Martin JE, Broen JC, Carmona FD, Teruel M, Simeon CP, Vonk MC, et al Identification of CSK as a systemic sclerosis genetic risk factor through genome-wide association study follow-up. Hum Mol Genet. 2012;21:2825-35.

10. Orozco G, Sánchez E, González-Gay MA, López-Nevot MA, Torres B, Cáliz R, et al. Association of a functional single-nucleotide polymorphism of PTPN22, encoding lymphoid protein phosphatase, with rheumatoid arthritis and systemic lupus erythematosus. Arthritis Rheum. 2005;52:219-24.

11. Rodríguez-Rodríguez L, Taib WR, Topless R, Steer S, González-Escribano MF, Balsa A, et al. The PTPN22 R263Q polymorphism is a risk factor for rheumatoid arthritis in Caucasian case-control samples. Arthritis Rheum. 2011;63:365-72.

12. Serrano A, Márquez A, Mackie SL, Carmona FD, Solans R, Miranda-Filloy JA, et al. Identification of the PTPN22 functional variant R620W as susceptibility genetic factor for giant cell arteritis. Ann Rheum Dis. 2013;72:1882-6.

13. Baranathan V, Stanford MR, Vaughan RW, Kondeatis E, Graham E, Fortune F, et al. The association of the PTPN22 $620 \mathrm{~W}$ polymorphism with Behcet's disease. Ann Rheum Dis. 2007:66:1531-3.

14. Martorana D, Maritati F, Malerba G, Bonatti F, Alberici F, Oliva E, et al. PTPN22 R620W polymorphism in the ANCA-associated vasculitides. Rheumatology (Oxford). 2012;51:805-12.
15. Orozco G, Miranda-Filloy JA, Martin J, Gonzalez-Gay MA. Lack of association of a functional single nucleotide polymorphism of PTPN22, encoding lymphoid protein phosphatase, with susceptibility to Henoch-Schönlein purpura. Clin Exp Rheumatol. 2007;25:750-3.

16. Michel BA, Hunder GG, Bloch DA, Calabrese LH. Hypersensitivity vasculitis and Henoch-Schonlein purpura: a comparison between the 2 disorders. J Rheumatol. 1992;19:721-8.

17. Mills JA, Michel BA, Bloch DA, Calabrese LH, Hunder GG, Arend WP, et al. The American College of Rheumatology 1990 criteria for the classification of Henoch-Schonlein purpura. Arthritis Rheum. 1990;33:1114-21.

18. Institute of Human Genetics. http://ihg.gsf.de/cgi-bin/hw/hwa1.pl.

19. Center for Statistical Genetics. http://www.sph.umich.edu/csg/abecasis/CaTS/.

20. Jennette JC, Falk RJ, Bacon PA, Basu N, Cid MC, Ferrario F, et al. Revised International Chapel Hill Consensus Conference Nomenclature of Vasculitides. Arthritis Rheum. 2013;2012:1-11.

21. Begovich AB, Caillier SJ, Alexander HC, Penko JM, Hauser SL, Barcellos LF, et al. The R620W polymorphism of the protein tyrosine phosphatase PTPN22 is not associated with multiple sclerosis. Am J Hum Genet. 2005;76:184-7.

22. Orozco G, Garcia-Porrua C, Lopez-Nevot MA, Raya E, Gonzalez-Gay MA, Martin J. Lack of association between ankylosing spondylitis and a functional polymorphism of PTPN22 proposed as a general susceptibility marker for autoimmunity. Ann Rheum Dis. 2006;65:687-8.

\section{Submit your next manuscript to BioMed Central and take full advantage of:}

- Convenient online submission

- Thorough peer review

- No space constraints or color figure charges

- Immediate publication on acceptance

- Inclusion in PubMed, CAS, Scopus and Google Scholar

- Research which is freely available for redistribution 